\title{
Volatile Changes during Storage of Shelf Stable Apple Juice: Integrating GC-MS Fingerprinting and Chemometrics
}

\author{
Biniam Kebede ${ }^{1, *}$, Vivien Ting ${ }^{1}$, Graham Eyres ${ }^{1}$ (I) and Indrawati Oey ${ }^{1,2}$ (I) \\ 1 Department of Food Science, University of Otago, PO BOX 56, Dunedin 9054, New Zealand; \\ vivientsy21@gmail.com (V.T.); graham.eyres@otago.ac.nz (G.E.); indrawati.oey@otago.ac.nz (I.O.) \\ 2 Riddet Institute, Private Bag 11 222, Palmerston North 4442, New Zealand \\ * Correspondence: biniam.kebede@otago.ac.nz; Tel.: +64-3-479-7257
}

Received: 23 December 2019; Accepted: 6 February 2020; Published: 10 February 2020

\begin{abstract}
This is the first study to reveal potential markers for volatile changes during ambient and accelerated shelf life of pasteurized apple juice. The volatile changes were monitored at 20, 30 and $40{ }^{\circ} \mathrm{C}$ using a headspace solid-phase microextraction-gas chromatography-mass spectrometry fingerprinting method. Using modern chemometrics and feature selection, hexanal, trans-2-hexenal, dimethyl sulphide, furfural, ethyl acetate and 1-pentanol were chosen as potential shelf life markers. Volatiles associated with the green, grassy and fresh apple aroma, such as hexanal and trans-2-hexenal, decreased during storage, whereas thermal load and browning associated compounds, like dimethyl sulphide and furfural, increased during storage. Hexanal and trans-2-hexenal can be markers to monitor the change in green-apple like character. Furfural and dimethyl sulphide can be markers of temperature abuse during juice processing and storage. Furfural can also be an indicator for juice browning. The present work effectively identified potential markers to monitor and predict volatile aroma changes of shelf stable apple juice in different storage conditions. Sensory analysis can be conducted in the future to confirm the aroma relevance of selected markers.
\end{abstract}

Keywords: apple juice; volatiles; shelf life; fingerprinting; chemometrics; chemical reactions

\section{Introduction}

Aroma is one of the most important quality attributes of an apple, which is mainly attributed to its volatile profile. Hundreds of volatile compounds have been detected in the aroma profile of apples. These compounds are categorized as esters, alcohols, aldehydes, ketones and ethers [1,2]. Some of these compounds are labeled as "character impact," including trans-2-hexenal (green), hexanal (grassy, green), butyl acetate (red apple aroma), ethyl butanoate (fruity), butan-1-ol (sweet aroma), etc. [3].

A large quantity of harvested apples can be processed into a juice. Thermal processing, using the high temperature short time principle, is still the most common method of preservation for an apple juice. This process results in a shelf stable product with a shelf life up to several months (when stored under the recommended conditions). Quality-related (bio)chemical reactions triggered during juicing and/or processing will continue during the storage time, thus the aroma of apple juice will further change during shelf life. Specifically, reactions such as oxidation and Maillard could lead to the loss of the fresh apple juice aroma and/or formation of off-odor or cooked-note during shelf life. However, based on our knowledge, no study could be found in literature investigating volatile changes during ambient and accelerated shelf life of pasteurized apple juice. Very few studies are available investigating the volatile changes during refrigerated shelf life of minimally processed apple juice $[4,5]$. Therefore, there remains a need for a method and a chemical marker, which would serve as a useful index of volatile aroma changes during ambient and accelerated shelf life of pasteurized apple juice. 
Numerous studies have focused on fresh apple juice flavor profiles [6-8]; comparing volatile profile of different cultivars [9,10]; effect of harvest date on volatiles compounds [11] and the influence of processing on the aroma [5,12-14]. However, no studies investigated volatile aroma changes during ambient and accelerated shelf life conditions of processed apple juice. In that framework, the aim of this study was to implement a gas chromatography-mass spectrometry (GC-MS) fingerprinting approach to track volatile changes in pasteurized apple juice during storage and determine reliable shelf life markers/indices. As a case study, a New Zealand Royal Gala apple was chosen. After thermal pasteurization, juices were stored at 20,30 and $40{ }^{\circ} \mathrm{C}$ to set-up accelerated shelf life testing (ASLT). A headspace solid-phase microextraction-gas chromatography-mass spectrometry (HS-SPME-GC-MS) fingerprinting methodology was implemented to detect a wide range of volatile compounds in the shelf stable apple juice headspaces. SPME is one of the most commonly used extraction techniques due to its sensitivity and selectivity and solvent-free nature. In this work, SPME using a divinylbenzene/carboxen/polydimethylsiloxane (DVB/CAR/PDMS) fibre coating was chosen due to its proven ability to detect a wide range of volatile compounds [15-19]. The obtained volatile fingerprinting data was analysed using advanced chemometrics methods. The state-of-the-art chemometrics and feature selection techniques [16-19] were used to track the volatile changes during storage and identify potential shelf life markers.

\section{Materials and Methods}

\subsection{Sample Preparation, Thermal Pasteurization and Stroage}

A single batch of Royal Gala apple was obtained from Mill's Orchard, Rangiora, New Zealand. After juicing, ascorbic acid ( $500 \mathrm{mg} / \mathrm{L})$ was added into the apple juice to minimize enzymatic browning. The juice was then pasteurized at $86{ }^{\circ} \mathrm{C}$ for $22 \mathrm{~s}$ (HIPEX UHT/Pasteurizing Pilot Plant, FoodSouth, Christchurch, New Zealand) and aseptically packed into sterile aluminum pouches (1 L/bag) via an Engi-O aseptic filler. Pasteurized shelf stable juices were then stored at three temperatures $(20,30$ and $40^{\circ} \mathrm{C}$ ) for up to 16 weeks to set up an ASLT. At fixed points in time (a maximum of eleven at each storage temperature), stored bags were sampled from the incubators. The detailed sampling plan can be found in the supplementary material (see Table S1). Prior to opening, the bags were cooled at $4{ }^{\circ} \mathrm{C}$ for $2 \mathrm{~h}$. Thereafter, samples were frozen in liquid nitrogen and stored at $-40{ }^{\circ} \mathrm{C}$. All stored samples were analyzed together in a single batch after the completion of the shelf life.

\subsection{Headspace Gas Chromatography-Mass Spectrometry (GC-MS) Fingerprinting Analysis}

Headspace-solid phase microextraction (HS-SPME) procedure was conducted according to Buvé, Neckebroeck, Haenen, Kebede, Hendrickx, Grauwet and Van Loey [18] with some modifications. Frozen samples were gently thawed overnight in a cooling room at $4{ }^{\circ} \mathrm{C}$. An aliquot of $8 \mathrm{~mL}$ apple juice was added into a $20 \mathrm{~mL}$ GC glass vial with polytetrafluoroethylene (PTFE)/silicone septum and crimp caps. Volatile compounds were extracted using headspace-solid phase micro-extraction (HS-SPME) method, and analysed using the Agilent 6890N GC system connected to an Agilent MSD 5975 VL. Equilibration, extraction and desorption of volatile compounds were automated using an auto sampler. The juice in the vial was equilibrated at $40^{\circ} \mathrm{C}$ for $5 \mathrm{~min}$. Next, headspace volatiles were extracted using an SPME fiber with a 50/30 $\mu \mathrm{m}$ divinylbenzene/carboxen/polydimethylsiloxane (DVB/CAR/PDMS) polymer at $40{ }^{\circ} \mathrm{C}$ for $30 \mathrm{~min}$. The fibre was conditioned and cleaned as recommended by the suppliers. Four independent SPME extractions were performed for each sample. Following extraction, the volatile compounds were thermally $\left(230{ }^{\circ} \mathrm{C}\right.$ during $5 \mathrm{~min}$ ) desorbed at the GC-inlet in a splitless mode. Separation was done using Zebron ZB-Wax column $(60 \mathrm{~m} \times 0.32 \mathrm{~mm}$ inner diameter $\times 0.5 \mu \mathrm{m}$ film thickness; Phenomenex) at a constant flow rate of $1 \mathrm{~mL} / \mathrm{min}$. The GC oven temperature was initially held at $50{ }^{\circ} \mathrm{C}$ for $5 \mathrm{~min}$, followed by heating at $5{ }^{\circ} \mathrm{C} / \mathrm{min}$ to reach $210{ }^{\circ} \mathrm{C}$, and then further ramped at $10{ }^{\circ} \mathrm{C} / \mathrm{min}$ to reach the final $240{ }^{\circ} \mathrm{C}$ and maintained for the next $5 \mathrm{~min}$ before cooling to $50{ }^{\circ} \mathrm{C}$. Electron ionisation at $70 \mathrm{eV}$ was used to obtain the mass spectra with a scanning range of 35 to $400 \mathrm{~m} / \mathrm{z}$. 
The mass spectrometry ion source and MS quadrupole temperature was set at $230{ }^{\circ} \mathrm{C}$ and $150{ }^{\circ} \mathrm{C}$, respectively. In the present work, samples were analyzed in a randomized fashion. Furthermore, day 0 (unstored) juice samples were injected into every 10 GC-MS analyses as a quality control (QC) sample. Blank samples were also used to monitor any carryover and integrity of the fibre.

\subsection{Chemometrics Data Analysis}

\subsubsection{Data Pre-Processing: From Chromatogram to Data Table}

As described by Kebede, Grauwet, Tabilo-Munizaga, Palmers, Vervoort, Hendrickx and Van Loey [16], Kebede, et al. [20] and Buvé, Neckebroeck, Haenen, Kebede, Hendrickx, Grauwet and Van Loey [18], the raw GC-MS total ion chromatogram was processed using automated mass spectral deconvolution and identification system (AMDIS, version 2.72, 2014, Agilent Technologies, USA) and mass profiler professional (MPP, version 14.9.1, 2017, Agilent Technologies, Australia) software. AMDIS was used to deconvolute peaks. MPP was then applied to filter out non-reproducible and irregular peaks and to align peaks.

\subsubsection{Chemometrics and Marker Selection}

The data obtained from MPP was analyzed using chemometrics data analysis which was carried out in Solo (Version 6.5, 2018, Eigenvector Research, Wenatchee, WA, USA). As discussed by Kebede, et al. [21] and Buvé, Neckebroeck, Haenen, Kebede, Hendrickx, Grauwet and Van Loey [18], two types of chemometrics techniques were employed: unsupervised principal component analysis (PCA) and supervised partial least squares regression (PLSR). The data was mean centered and scaled (weighed by their standard deviation). The unsupervised PCA was used to explore the data for any patterns and groupings and also to detect any outliers. Following that, PLSR was applied to study the evolution of volatiles in the headspace fraction during storage. For PLSR, the detected volatiles were considered as $X$-variables and storage time was considered as $Y$-variable. The optimum number of latent variables (LVs) for the model was selected using cross validation. To avoid the risk of overfitting, LVs that explain the maximum variance within the data at the minimum noise (root mean squared error; RMSE) were selected based on the applied cross validation. Bi-plots were constructed to visualize the volatile changes during storage. In order to select compounds significantly changing during storage (potential shelf life markers), variable identification (VID) coefficients were calculated. VID estimates the correlation coefficient between the detected volatiles and storage time. To identify compounds significantly affected by storage time, volatiles with an absolute VID value higher than 0.750 were selected and identified. To confirm the identity, three criteria were employed: (a) matching retention time and spectra with injected reference standards for at least one volatile from each chemical class; (b) comparison of the experimental retention index (RI) with RI according to literature; (c) match with the NIST library (NIST14, version 2.2, National Institute of Standards and Technology, Gaithersburg, MD, USA) of not less than $90 \%$ fit quality. For the RI calculation, alkanes were injected on the same ZB-Wax column and a maximum deviation of $<30$ was used to support compound identifications.

\section{Results and Discussion}

\subsection{Analyzing Volatile Changes during Storage of Shelf Stable Apple Juice}

A representative total ion chromatogram of pasteurized apple juice obtained with the HS-SPME-GC-MS fingerprinting is depicted in Figure 1. The fingerprinting method enabled a detection of 70 volatile compounds in the pasteurized apple juice headspace, including esters, aldehydes, alcohols, carboxylic acid, ketones, etc. Comparable volatile compounds chemical groups have been reported in several apple cultivars $[3,22,23]$. 


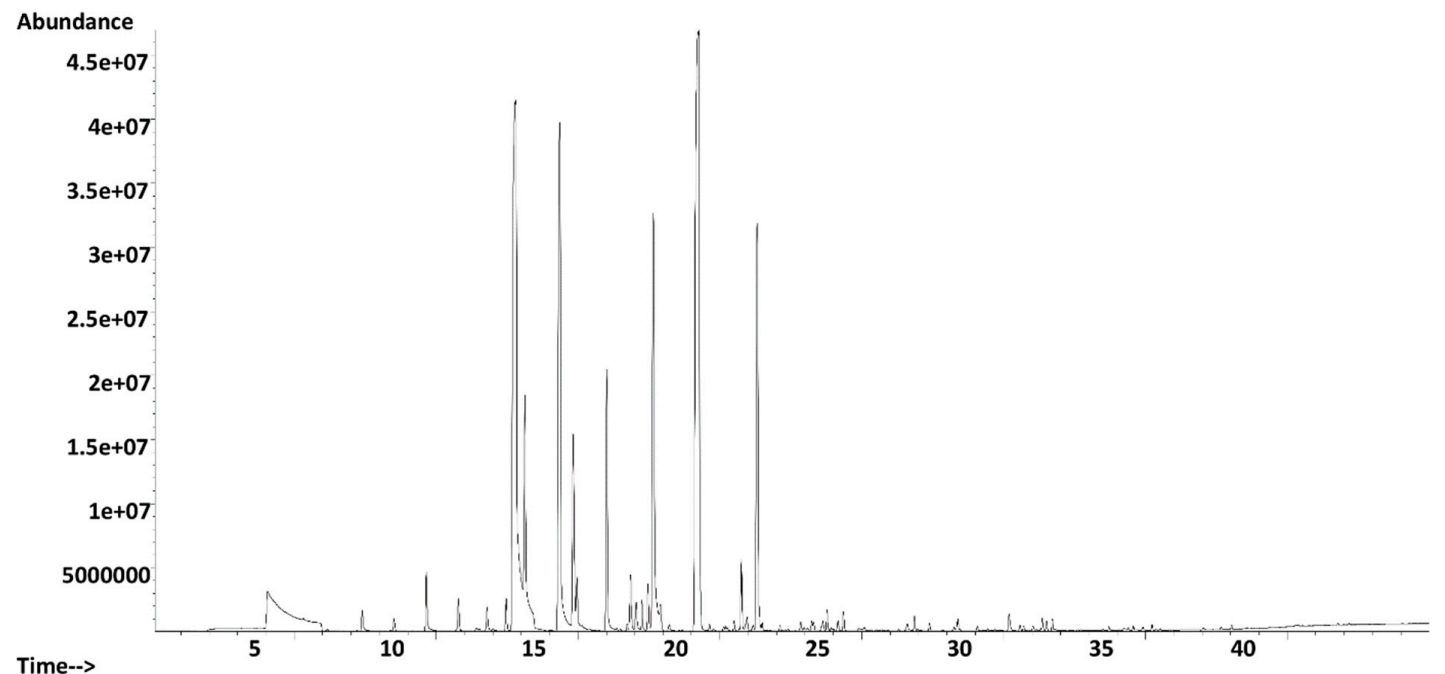

Figure 1. An exemplary total ion chromatogram of a volatile fraction of pasteurized apple juice obtained by the headspace solid-phase microextraction-gas chromatography-mass spectrometry (HS-SPME-GC-MS) fingerprinting method.

The data was analyzed using chemometrics software called Solo (Version 6.5, 2018, Eigenvector Research, Wenatchee, WA, USA). The data was mean centered and scaled (weighed by their standard deviation). The unsupervised PCA was used to explore the data for any patterns and groupings and to detect outliers. In this work, a PCA model using three principal components showed a clear trend in all storage temperatures. As can be seen from the PCA bi-lots (Figure S1), the headspace fraction of the pasteurized apple juice changed as a function of storage time (from day 0 to week 16) and the trend was slightly clearer at higher storage temperatures. Furthermore, no outliers could be detected using PCA.

PLSR was applied to further study the evolution of volatiles in the headspace fraction during storage and determine reliable shelf life markers. In PLSR, both the $X$-variables (detected volatile compounds) and $Y$-variable (storage time) data are considered (in PCA, only $X$-variables are considered). The goal of a PLSR analysis was to correlate volatile compounds and storage time using a linear multivariate model. Cross validation was used to choose the optimum number latent variables (LVs) for the PLSR that maximally describe the variation with a minimum noise. Using contiguous blocks cross validation, two LVs were selected as optimum, explaining more than $95 \%$ of the $Y$-variance in all storage temperatures. Based on the models, three bi-plots, one for each temperature, were constructed to visualize the volatile changes during storage (Figure 2). 

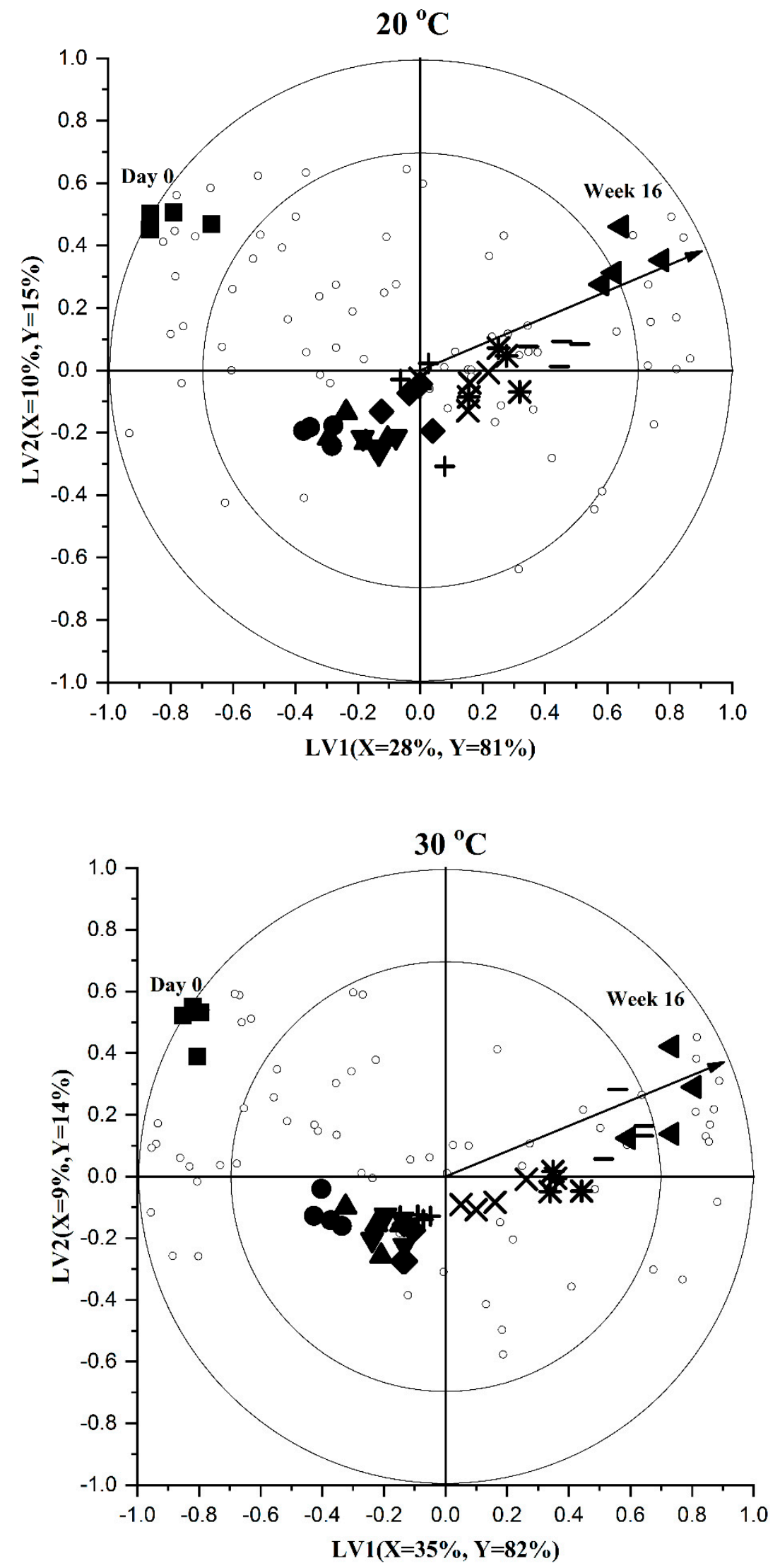

Figure 2. Cont.. 


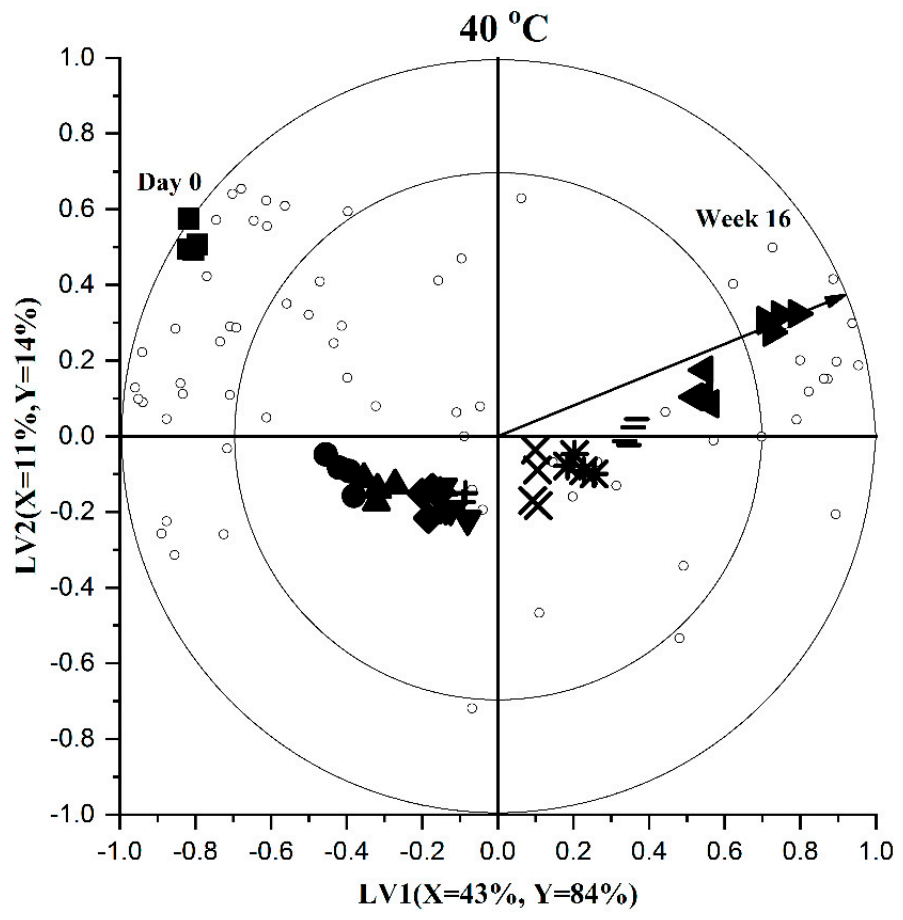

Figure 2. Partial least squares regression (PLSR) bi-plots visualising volatile changes in the headspace fraction of pasteurized apple juice during storage at 20,30 and $40{ }^{\circ} \mathrm{C}$. Up to 11 sampling points were used during storage at each storage temperatures (details are attached in the supplementary): time 1 $(\boldsymbol{\bullet})$; time $2(\bullet)$; time $3(\mathbf{\Delta})$; time $4(\mathbf{v})$; time $5(\bullet)$; time $6(+)$; time $7(\mathrm{X})$; time $8\left(^{*}\right)$; time $9(-)$; time $10(\bullet)$; time $11(\bullet)$. The $X$ and $Y$-variances represented by latent variables (LV)1 and LV2 are shown.

These bi-plots show a comparable trend for the PCA plots, in which there is a clear effect of storage time on the apple juice volatile compounds at all storage temperatures. As discussed before, the trend seems to become slightly clearer at high storage temperatures indicating an effect of temperature in addition to storage time. On the bi-plots, the unfilled small circles represent the volatile compounds. Some of these compounds are positioned close to day 0 samples and others are projected towards the end of storage time. This seems to suggest that the concentration of some of the volatile compounds have decreased during storage while some other compounds appear to be formed/increased.

Furthermore, when closely examining the bi-plots, two trends can be seen. The first one is the horizontal projection of the samples from start (day 0 ) to the end (week 16) of storage time. This clear horizontal trend (variation) is represented by the first LV (> $80 \%$ of the $Y$-variance at all three storage temperatures). The second trend on the bi-plots is the V-shaped structure of the samples, which seems to be explained by the second LV. Such trends indicate the presence of possible complex (bio)chemical changes. In general, the bi-plots demonstrate that multiple complex degradation and formation reactions occur during storage of pasteurized apple juice. Comparable complex trends were previously reported when studying chemical changes during shelf life of pasteurized orange juice [24], pasteurized strawberry juice [18] and sterilized carrot purees [20].

The bi-plot is a powerful tool to graphically observe and interpret the evolution of volatiles as a function of storage time. However, the aim of this study was to identify volatile compounds affected by the storage time and temperature, which could be used as potential shelf life markers. Hence, feature selection was performed using a variable identification (VID) technique [17,18]. VID estimates the correlation coefficient between the detected volatile compounds and storage time. In other words, VID will enable the determination of headspace compounds significantly changing during storage. Aiming for compounds significantly affected by storage, variables with an absolute VID coefficient value higher than 0.750 were chosen (Table 1). These compounds were identified. 
Table 1. Headspace compounds significantly changing during storage at each $20{ }^{\circ} \mathrm{C}, 30{ }^{\circ} \mathrm{C}$ and $40^{\circ} \mathrm{C}$ storage temperatures. Volatiles selected as potential shelf life markers/indices are put in bold. The retention index (RI) and chemical family are also listed. The identity of these compounds was further confirmed by injecting pure standard on the same GC-MS method.

\begin{tabular}{|c|c|c|c|c|}
\hline $\begin{array}{c}\text { Storage } \\
\text { Temperature }\end{array}$ & VID & Identity & $\begin{array}{l}\text { RI (Zebron } \\
\text { ZB-Wax) }\end{array}$ & Chemical Group \\
\hline \multirow[t]{9}{*}{$20^{\circ} \mathrm{C}$} & -0.953 & Hexanal & 1077 & Aldehyde \\
\hline & -0.751 & Trans-2-hexenal & 1242 & Aldehyde \\
\hline & -0.750 & 5-Hexenyl acetate & 1357 & Ester \\
\hline & 0.754 & 1-Pentanol & 1263 & Alcohol \\
\hline & 0.777 & Hexanoic acid & 1851 & Carboxylic acid \\
\hline & 0.797 & Ethyl acetate & 866 & Ester \\
\hline & 0.837 & 2,4-Di-tert-butylphenol & 2143 & Phenol \\
\hline & 0.901 & Furfural & 1508 & Furan \\
\hline & 0.922 & Dimethyl sulphide & 790 & Sulfur compound \\
\hline \multirow[t]{16}{*}{$30^{\circ} \mathrm{C}$} & -0.959 & Hexanal & 1077 & Aldehyde \\
\hline & -0.919 & (E)-2-hexen-1-ol & 1434 & Alcohol \\
\hline & -0.914 & 5-Hexenyl acetate & 1357 & Ester \\
\hline & -0.897 & Trans-3-hexenyl acetate & 1347 & Ester \\
\hline & -0.878 & 2-Hexen-1-ol, acetate & 1364 & Ester \\
\hline & -0.838 & 3-Methyl-3-buten-1-ol, acetate & 1209 & Ester \\
\hline & -0.831 & Trans-2-hexenal & 1242 & Aldehyde \\
\hline & -0.806 & Butyl propionate & 1144 & Ester \\
\hline & -0.792 & Amyl acetate & 1182 & Ester \\
\hline & 0.838 & Hexanoic acid & 1851 & Carboxylic acid \\
\hline & 0.846 & Ethyl acetate & 866 & Ester \\
\hline & 0.853 & 2-Methyl-1-butanol & 1213 & Alcohol \\
\hline & 0.860 & 2,4-Di-tert-butylphenol & 2143 & Phenol \\
\hline & 0.875 & 1-Pentanol & 1263 & Alcohol \\
\hline & 0.891 & Furfural & 1508 & Furans \\
\hline & 0.933 & Dimethyl sulphide & 790 & Sulfur compound \\
\hline \multirow[t]{17}{*}{$40{ }^{\circ} \mathrm{C}$} & -0.923 & 3-Methyl-3-buten-1-ol, acetate & 1209 & Ester \\
\hline & -0.913 & Trans-3-hexenyl acetate & 1347 & Ester \\
\hline & -0.911 & 5-Hexenyl acetate & 1357 & Ester \\
\hline & -0.904 & Isobutyl acetate & 990 & Ester \\
\hline & -0.901 & Hexanal & 1077 & Aldehyde \\
\hline & -0.901 & N-pPropyl acetate & 949 & Ester \\
\hline & -0.876 & 2-Hexen-1-ol, acetate & 1364 & Ester \\
\hline & -0.849 & Amyl acetate & 1182 & Ester \\
\hline & -0.793 & 3-(Methylthio)propyl acetate & 1662 & Ester \\
\hline & -0.777 & Trans-2-hexenal & 1242 & Aldehyde \\
\hline & 0.829 & Hexanoic acid & 1851 & Carboxylic acid \\
\hline & 0.833 & 2-Octanone & 1315 & Hydrocarbon \\
\hline & 0.875 & 1-Bromo-2-methyl-cyclohexane & 1281 & Hydrocarbon \\
\hline & 0.885 & 2-Methyl-1-butanol & 1213 & Alcohol \\
\hline & 0.917 & 1-Pentanol & 1263 & Alcohol \\
\hline & 0.972 & Dimethyl sulphide & 790 & Sulfur compound \\
\hline & 0.978 & Furfural & 1508 & Furan \\
\hline
\end{tabular}

GC-MS: gas chromatography-mass spectrometry; VID: Variable identification.

\subsection{Potential Markers of Aroma Changes during Storage of Shelf Stable Apple Juice}

In samples stored at 20,30 and $40{ }^{\circ} \mathrm{C}$, respectively, 9, 16 and 17 volatile compounds were selected based on the VID technique. The selected compounds can be categorized as aldehyde, ester, sulphur compound, furan, alcohol and carboxylic acid chemical families. Most of these volatile compounds have been detected in the headspace of several apple varieties [3,22]. Aldehydes such as hexanal and trans-2-hexenal and most ester compounds were selected with negative VID coefficients, indicating the concentrations of these compounds have decreased during storage. On the other side, volatiles from sulphur compound, furan, alcohol and carboxylic acid chemical families have shown an increasing/formation trend as a function of storage time (selected with positive VID values).

When comparing the selected compounds among the 20,30 and $40^{\circ} \mathrm{C}$ storage temperatures, similar chemical groups were selected. This seems to suggest the presence of comparable reaction pathways 
at all storage temperatures. Moreover, more volatiles were selected at higher storage temperatures compared to the ambient condition. In the present work, two criteria were used for choosing potential shelf life markers/indices: (i) the peak area must change not only at higher storage temperature but also at the ambient condition (to verify the applicability for ASLT); and (ii) be characteristic aroma compounds in fresh and/or processed apple juice. Based on these criteria, hexanal, trans-2-hexenal, dimethyl sulphide, furfural, ethyl acetate and 1-pentanol were chosen as potential markers for volatile flavor changes during shelf life of processed apple juice.

Figure 3 shows the evolution during storage of these potential shelf life marker compounds at the three storage temperatures. The peak area obtained after peak deconvolution using AMDIS was used to investigate the changes. The changes are influenced by both storage time and temperature. On the one hand, the amount of hexanal and trans-2-hexenal have decreased during storage. On the other hand, dimethyl sulphide, furfural, 1-pentanol and ethyl acetate have shown an increasing trend as a function of storage time. Buvé, Neckebroeck, Haenen, Kebede, Hendrickx, Grauwet and Van Loey [18] have also observed a decreasing trend for aldehydes such as hexanal, trans-2-hexenal and an increasing trend for furfural and dimethyl sulphide during shelf life for pasteurized strawberry juice. There is limited literature information reporting the changes in these compounds during shelf life of pasteurized apple juice. Nevertheless, to obtain an insight into the shelf life changes, the evolution of some of these markers was interpreted and discussed in relation to relevant (bio)chemical reactions based on available information on other citrus juices.

Hexanal and trans-2-hexenal are associated with "green," "grassy" and "fresh" character in several apple cultivars [3]. From Figure 3, at the start of storage these compounds seem to appear at higher amounts in pasteurized apple juice. During storage, however, the amounts of these compounds decreased to lower levels, possibly due to oxidative breakdown processes. This shows the significant effect of shelf life, and that process impact evaluations should not only be investigated immediately after processing but also during shelf life. Buvé, Neckebroeck, Haenen, Kebede, Hendrickx, Grauwet and Van Loey [18] have also reported a fast degradation of hexanal and 2-hexenal during storage of pasteurized strawberry puree. The loss of these compounds could result in the loss of the fresh, green and grassy note of the apple juice during storage. Sensory analysis needs to be conducted to confirm this hypothesis, but the output from this work shows that hexanal and trans-2-hexenal can be used as potential shelf life markers of the green-apple like character.

The concentration of ethyl acetate has shown an increasing trend during storage. Previous studies have reported a decrease in the volatile release of trans-2-hexenal and an increase in acetate esters during enzymatic browning of apple juice. The authors have associated this trend to a decrease in green odour and an increase of sweet odour during browning [25]. A similar trend can be hypothesized in the present work. However, this needs to be further confirmed with a sensory analysis.

Furfural has been reported as an index of storage temperature abuse in commercially processed citrus juices [26]. In the present work the amount of furfural was low at the beginning of storage and has shown an increasing trend as a function of storage time and temperature. In citrus fruit juices, furfural is reported to stem from the decomposition of ascorbic acid. In literature, both aerobic and anaerobic degradation of ascorbic acid have been linked with furfural formation. The oxidative reaction involves degradation of ascorbic acid to dehydroascorbic acid, followed by hydration of dehydroascorbic acid to ketogluconic acid, and finally decarboxylation and dehydration to furfural. Non-oxidative degradation occurs under acidic conditions, in which ascorbic acid degrades into furfural and 3-deoxy-L-pentose [27,28]. Furthermore, furfural has been considered an important intermediate and indicator of browning of orange juices [29]. Hence, the present work indicates the potential of furfural to be used as an important shelf life index/marker of temperature abuse and browning of pasteurized apple juice.

Dimethyl sulphide is selected with a high VID coefficient at all storage temperatures, which shows that its amount has increased during storage time. The formation of dimethyl sulphide is associated with reactions involving sulphur containing amino acids, such as methionine. During high 
temperature processing and storage conditions, methionine breaks down and further oxidises into dimethyl sulphide [30]. This compound has been reported with a strong relation to the thermal load of processing and/or storage conditions. Wibowo, Grauwet, Kebede, Hendrickx and Van Loey [24], Buvé, Neckebroeck, Haenen, Kebede, Hendrickx, Grauwet and Van Loey [18] and Kebede, Grauwet, Palmers, Vervoort, Carle, Hendrickx and Van Loey [21] have also reported an increased formation of dimethyl sulphide during storage (above $20^{\circ} \mathrm{C}$ ) of pasteurized orange juice, pasteurized strawberry puree and sterilized carrot puree, respectively. As dimethyl sulphide can give rise to an unwanted cooked-note, conditions that can lead to temperature abuse should be minimized throughput the whole production and supply chain. The present work shows that dimethyl sulphide can be used as a reliable shelf life indicator of temperature abuse during storage of processing apple juice.

1-Pentanol is another volatile showing an increasing trend during storage. This increasing trend is affected by temperature, but at a lower extent when compared to furfural and dimethyl sulphide. Contrary to furfural and dimethyl sulphide, 1-pentanol was already detected at a relatively higher amount at the beginning of storage (immediately after processing). This seems to suggest that the reactions responsible for this compound have already been triggered during juice and/or pasteurization steps. Possibly this formation could be due to an oxidative reaction triggered and continued during storage. 

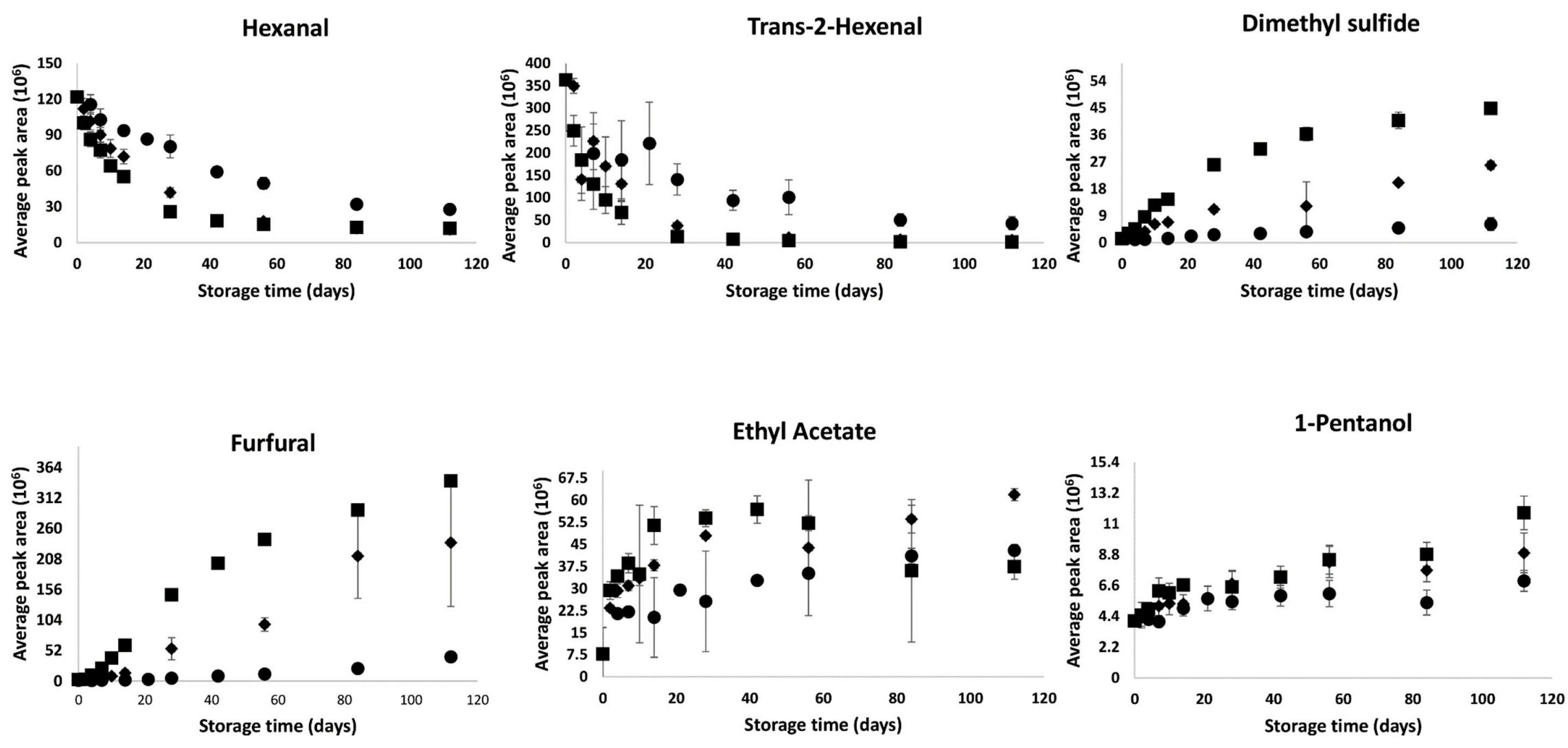

Figure 3. Average peak area of potential shelf life markers during storage in pasteurized apple juice stored at $20^{\circ} \mathrm{C}(\bullet), 30{ }^{\circ} \mathrm{C}(\bullet)$ and $40{ }^{\circ} \mathrm{C}(\boldsymbol{\bullet})$. Standard deviation of 4 individual headspace extraction is included. 


\section{Conclusions}

This study obtained an increased insight into volatile changes during storage (at 20, 30 and $40{ }^{\circ} \mathrm{C}$ ) of shelf stable apple juice. Using HS-SPME-GC-MS fingerprinting, 70 volatile compounds could be effectively detected in pasteurized apple juice. Advanced chemometrics and feature selection techniques revealed potential markers for volatile aroma changes during storage. These compounds can be grouped under aldehyde (e.g., hexanal, trans-2-hexenal), sulfur compound (dimethyl sulphide), furans (furfural), ester (ethyl acetate) and alcohol (1-pentanol) chemical groups. Volatile markers associated with the grassy, green and fresh apple aroma (e.g., hexanal, trans-2-hexenal) seem to decrease during storage, whereas thermal-load (e.g., dimethyl sulphide) and browning (e.g., furfural) indicator compounds increased during storage. The selected compounds were also affected by the storage temperature. Furthermore, most of these compounds are odour-active volatiles. This seems to suggest their potential to be used as markers for accelerated shelf life testing of pasteurized apple juice. Hexanal and trans-2-hexenal can be potential markers to monitor the loss in green-apple like character. Furfural and dimethyl sulphide can be markers of temperature abuse. Furfural can also be an indicator for juice browning. The present work effectively identified potential markers/indices to monitor, optimize and predict volatile aroma changes of shelf stable apple juice in different storage conditions. In the future, the kinetics of selected shelf-life compounds should be studied in the context of accelerated shelf-life testing (ASLT). Furthermore, based on the obtained results, it is less straightforward to associate the changes in the selected markers to overall apple juice flavor. In the future, there is a need to conduct a sensorial analysis to understand how the observed volatile changes will be perceived. Furthermore, there is a need to investigate the volatile changes and selected markers in other apple cultivars.

Supplementary Materials: The following are available online at http://www.mdpi.com/2304-8158/9/2/165/s1, Figure S1: PCA bi-plots showing volatile changes in pasteurized apple juice during storage at 20,30 and $40^{\circ} \mathrm{C}$. The X-variances explained by each latent variable (LVs) are shown. Arrow is included to clearly show the trend as a function of storage time, Table S1: Details of shelf life planning. At fixed points in time (up to 11 time points per temperature), stored bags were sampled from the incubators.

Author Contributions: Conceptualization, B.K.; data curation, V.T.; funding acquisition, B.K.; investigation, V.T.; methodology, B.K. and G.E.; project administration, B.K.; resources, B.K., G.E. and I.O.; software, B.K.; validation, B.K., G.E. and I.O.; writing - original draft, B.K. and G.E.; writing - review \& editing, V.T. and I.O. All authors have read and agreed to the published version of the manuscript.

Funding: This work was financially supported by the University of Otago Research Grant (2018 UORG).

Acknowledgments: The authors thank Michelle Leus and Ian Ross for their laboratory assistance and acknowledge Agilent for providing the Mass Profiler professional (MPP) software. The authors thank Nick and Carey White, Mill's Orchard, Rangiora, New Zealand for providing the Royal Gala apple in kind.

Conflicts of Interest: The authors declare no conflict of interest.

\section{References}

1. Espino-Díaz, M.; Sepúlveda, D.R.; González-Aguilar, G.; Olivas, G.I. Biochemistry of apple aroma: A review. Food Technol. Biotechnol. 2016, 54, 375-397. [CrossRef] [PubMed]

2. Perestrelo, R.; Silva, C.; Silva, P.; Medina, S.; Câmara, J.S. Differentiation of fresh and processed fruit juices using volatile composition. Molecules 2019, 24, 974. [CrossRef] [PubMed]

3. Dixon, J.; Hewett, E.W. Factors affecting apple aroma/flavour volatile concentration: A review. N. Z. J. Crop Hortic. Sci. 2000, 28, 155-173. [CrossRef]

4. Kebede, B.; Lee, P.Y.; Leong, S.Y.; Kethireddy, V.; Ma, Q.; Aganovic, K.; Eyres, G.T.; Hamid, N.; Oey, I. A chemometrics approach comparing volatile changes during the shelf life of apple juice processed by pulsed electric fields, high pressure and thermal pasteurization. Foods 2018, 7, 169. [CrossRef] [PubMed]

5. Yi, J.J.; Kebede, B.T.; Dang, D.N.H.; Buve, C.; Grauwet, T.; Van Loey, A.; Hu, X.S.; Hendrickx, M. Quality change during high pressure processing and thermal processing of cloudy apple juice. LWT-Food Sci. Technol. 2017, 75, 85-92. [CrossRef] 
6. Abrodo, P.A.; Llorente, D.D.; Corujedo, S.J.; de la Fuente, E.D.; Álvarez, M.D.G.; Gomis, D.B. Characterisation of asturian cider apples on the basis of their aromatic profile by high-speed gas chromatography and solid-phase microextraction. Food Chem. 2010, 121, 1312-1318. [CrossRef]

7. Nikfardjam, M.P.; Maier, D. Development of a headspace trap hrgc/ms method for the assessment of the relevance of certain aroma compounds on the sensorial characteristics of commercial apple juice. Food Chem. 2011, 126, 1926-1933. [CrossRef]

8. Schmutzer, G.R.; Magdas, A.D.; David, L.I.; Moldovan, Z. Determination of the volatile components of apple juice using solid phase microextraction and gas chromatography-mass spectrometry. Anal. Lett. 2014, 47, 1683-1696. [CrossRef]

9. Aprea, E.; Gika, H.; Carlin, S.; Theodoridis, G.; Vrhovsek, U.; Mattivi, F. Metabolite profiling on apple volatile content based on solid phase microextraction and gas-chromatography time of flight mass spectrometry. J. Chromatogr. A 2011, 1218, 4517-4524. [CrossRef]

10. Xiaobo, Z.; Jiewen, Z. Comparative analyses of apple aroma by a tin-oxide gas sensor array device and gc/ms. Food Chem. 2008, 107, 120-128. [CrossRef]

11. Echeverría, G.; Fuentes, T.; Graell, J.; Lara, I.; López, M.L. Aroma volatile compounds of 'fuji' apples in relation to harvest date and cold storage technology: A comparison of two seasons. Postharvest Biol. Technol. 2004, 32, 29-44. [CrossRef]

12. Elss, S.; Preston, C.; Appel, M.; Heckel, F.; Schreier, P. Influence of technological processing on apple aroma analysed by high resolution gas chromatography-mass spectrometry and on-line gas chromatography-combustion/pyrolysis-isotope ratio mass spectrometry. Food Chem. 2006, 98, 269-276. [CrossRef]

13. Lee, P.Y.; Kebede, B.T.; Lusk, K.; Mirosa, M.; Oey, I. Investigating consumers' perception of apple juice as affected by novel and conventional processing technologies. Int. J. Food Sci. Technol. 2017, 52, 2564-2571. [CrossRef]

14. SU, S.K.; WILEY, R.C. Changes in apple juice flavor compounds during processing. J. Food Sci. 1998, 63, 688-691. [CrossRef]

15. Arcena, M.R.; Kebede, B.; Leong, S.Y.; Silcock, P.; Oey, I. Feasibility of using integrated fingerprinting, profiling and chemometrics approach to understand (bio) chemical changes throughout commercial red winemaking: A case study on merlot. Food Res. Int. 2020, 127, 108767. [CrossRef] [PubMed]

16. Kebede, B.T.; Grauwet, T.; Tabilo-Munizaga, G.; Palmers, S.; Vervoort, L.; Hendrickx, M.; Van Loey, A. Headspace components that discriminate between thermal and high pressure high temperature treated green vegetables: Identification and linkage to possible process-induced chemical changes. Food Chem. 2013, 141, 1603-1613. [CrossRef]

17. Vervoort, L.; Grauwet, T.; Kebede, B.T.; Van der Plancken, I.; Timmermans, R.; Hendrickx, M.; Van Loey, A. Headspace fingerprinting as an untargeted approach to compare novel and traditional processing technologies: A case-study on orange juice pasteurisation. Food Chem. 2012, 134, 2303-2312. [CrossRef]

18. Buvé, C.; Neckebroeck, B.; Haenen, A.; Kebede, B.; Hendrickx, M.; Grauwet, T.; Van Loey, A. Combining untargeted, targeted and sensory data to investigate the impact of storage on food volatiles: A case study on strawberry juice. Food Res. Int. 2018, 113, 382-391. [CrossRef]

19. Yi, J.; Kebede, B.; Kristiani, K.; Grauwet, T.; Van Loey, A.; Hendrickx, M. Minimizing quality changes of cloudy apple juice: The use of kiwifruit puree and high pressure homogenization. Food Chem. 2018, 249, 202-212. [CrossRef]

20. Kebede, B.T.; Grauwet, T.; Palmers, S.; Michiels, C.; Hendrickx, M.; Van Loey, A. Investigating chemical changes during shelf-life of thermal and high-pressure high-temperature sterilised carrot purees: A 'fingerprinting kinetics' approach. Food Chem. 2015, 185, 119-126. [CrossRef]

21. Kebede, B.T.; Grauwet, T.; Palmers, S.; Vervoort, L.; Carle, R.; Hendrickx, M.; Van Loey, A. Effect of high pressure high temperature processing on the volatile fraction of differently coloured carrots. Food Chem. 2014, 153, 340-352. [CrossRef] [PubMed]

22. Aprea, E.; Corollaro, M.L.; Betta, E.; Endrizzi, I.; Demattè, M.L.; Biasioli, F.; Gasperi, F. Sensory and instrumental profiling of 18 apple cultivars to investigate the relation between perceived quality and odour and flavour. Food Res. Int. 2012, 49, 677-686. [CrossRef] 
23. López, M.L.; Villatoro, C.; Fuentes, T.; Graell, J.; Lara, I.; Echeverría, G. Volatile compounds, quality parameters and consumer acceptance of 'pink lady ${ }^{\circledR}$ ' apples stored in different conditions. Postharvest Biol. Technol. 2007, 43, 55-66. [CrossRef]

24. Wibowo, S.; Grauwet, T.; Kebede, B.T.; Hendrickx, M.; Van Loey, A. Study of chemical changes in pasteurised orange juice during shelf-life: A fingerprinting-kinetics evaluation of the volatile fraction. Food Res. Int. 2015, 75, 295-304. [CrossRef]

25. Komthong, P.; Katoh, T.; Igura, N.; Shimoda, M. Changes in the odours of apple juice during enzymatic browning. Food. Qual. Prefer. 2006, 17, 497-504. [CrossRef]

26. Dinsmore, H.L.; Nagy, S. Colorimetric furfural measurement as an index of deterioration in stored citrus juices. J. Food Sci. 1972, 37, 768-770. [CrossRef]

27. Finholt, P.; Paulssen, R.B.; Higuchi, T. Rate of anaerobic degradation of ascorbic acid in aqueous solution. J. Pharm. Sci. 1963, 52, 948-954. [CrossRef]

28. Kanner, J.; Harel, S.; Fishbein, Y.; Shalom, P. Furfural accumulation in stored orange juice concentrates. J. Agric. Food Chem. 1981, 29, 948-949. [CrossRef]

29. Shinoda, Y.; Komura, H.; Homma, S.; Murata, M. Browning of model orange juice solution: Factors affecting the formation of decomposition products. Biosci. Biotechnol. Biochem. 2005, 69, 2129-2137. [CrossRef]

30. Perez-Cacho, P.R.; Mahattanatawee, K.; Smoot, J.M.; Rouseff, R. Identification of sulfur volatiles in canned orange juices lacking orange flavor. J. Agric. Food Chem. 2007, 55, 5761-5767. [CrossRef]

(C) 2020 by the authors. Licensee MDPI, Basel, Switzerland. This article is an open access article distributed under the terms and conditions of the Creative Commons Attribution (CC BY) license (http://creativecommons.org/licenses/by/4.0/). 